\title{
The analysis of the response from tertiary education programs to the challenges of the Fourth Industrial Revolution
}

\author{
Ioana Coralia ZAVERA \\ The Bucharest University of Economic Studies, Romania \\ zaveraioanacoralia@yahoo.com
}

PICBE |

1261

\begin{abstract}
One can find at the level of the specialized literature a heated debate on the metaphor that defines the status of the international economy and human society. Some analysts argue that the Third Industrial Revolution is currently undergoing an advanced stage, while others claim that due to the speed, scale and impact of the transformations that have taken place, the fourth industrial revolution has already begun. This paper analyzes how the artificial intelligence, personalized medicine, virtual reality or the internet of things are a few motors that fueled the advance to the Fourth Industrial Revolution and their impact on cognitive competencies, skills and abilities to guarantee tertiary education programs. The main analytical hypothesis is that technology is the one that encourages humanity to accelerate and focus on changes in other areas, especially that the risk of increasing gap between technological advance and in areas such education appears. The paper examines the concrete way in which transformations that follow a symbiosis of man with technology contribute to the configuration of a new paradigm to which the educational environment has to face with. The paper aims also to highlight the main challenges of the educational environment in relation to the fourth industrial revolution, and what are the necessary transformation for a good correlation of the human capital with technological progress. Emphasis is on new sets of skills, creativity, innovation, so that new business models can be developed and applied in a changing environment.
\end{abstract}

Keywords: the fourth industrial revolution, educational processes, artificial intelligence, new business model

\section{Introduction}

The recent phenomena have determined the evolution and revolution of a constantly changing society. Although the global environment is aware of the revolutions, the fourth industrial revolution seems to exceed the size of the three and have an impact in all disciplines, economies and industries, with technological influences in the physical, digital and biological worlds. If the three were to give up animal traction, the possibility of mass production and the knowledge of digital capabilities, the latter highlights the potential of a world that can connect billions of people to digital networks, which can improve efficiency in organizations and even manage assets to contribute to regenerate the natural environment, canceling the damage caused by previous industrial revolutions.

Professor Schwab invites leaders and citizens to "shape together a future that works for all by putting people first, empowering them and constantly reminding us that all of these new technologies are first and foremost tools made by people for people."

Although tertiary education has so far been designed to meet the needs arising from previous industrial revolutions (existing systems are not prepared to cope with the automated economy), it continues to play an important role in shaping the transitions through which societies move, needed to adapt to the fourth industrial revolution. Demographic change, health, literacy, climate change are some of the challenges facing the global environment in general and the educational environment particularly. Since artificial intelligence is gaining importance more and more, future jobs will involve the ability to work with it, so the specialization in the studies will not be the one that will make a career. 
The content and a deep understanding of it matters, but also what you can do following the election. The main objective of tertiary education is to develop capacities and keep knowledge among graduates for a productive life.

\section{Literature review}

In nowadays society, progress has become vital in all spheres and areas of activity, although there is no unanimously accepted definition of progress, depending on the area and context in which it is observed. Broadly defined, progress can be seen as a desirable future, with positive developments. Quantitative economic indicators are not sufficient, progressive indicators are becoming more and more important.

Given that investment is the engine of economic growth, and education is one of the environments that need investment, it is increasingly known the "new economy," in which ideas, knowledge, and social relationships are intangible assets in a tangible reality.

Tertiary education is constantly changing as a result of rapid developments in the global economy and the types of employees and thinkers required by the labor market and the business environment.

The main changes in the tertiary educational environment are highlighted as follows, taking into account the fourth industrial revolutions.

After the first industrial revolution, the vision of a new type of curriculum, with more qualification options and education programs to broaden the selection base, began to emerge. This type of education was described by Charles Eliot as "New Education" and provided a dramatic change from classical education in the Yale Report of 1828.

The second industrial revolution brought an extension of access to higher education and the development of several types of higher education institutions both in the United States and in Europe has led to an increase in discovery and helped to strengthen growth caused by new powerful technologies.

It is important to remember that changes in society and education are difficult to separate from other causes, such as economic cycles or geopolitical transformations (the expansion of the United States to the West, the development of Japan and Germany, and the global wars that have led to imbalances in economic activity and accelerated the development of science and technology). Some economists have noticed that the cyclical nature of economic activity results from regular economic growth cycles, followed by a recession called the Kondratiev cycles.

At the same time, economists have noted that whenever new technologies are introduced into an economy, there is a lag of delay until adaptation so as to have a significant impact on productivity. This gap between technological innovation and productivity growth is known as the productivity paradox and is associated with the time needed to train and experiment the new technology on a large scale (Atkeson and Kehoe, 2006). The development of new institutions and new programs has allowed technical and managerial capacity to expand the economy and production that emerged in the twentieth century.

The Third Industrial Revolution has introduced computerization and the Internet, developed in the 1980s and 1990s, and its effects still manifest today on society, politics, economics and education. Extending access to higher education has grown even more, with increased diversity in campuses and the globalization of academic research accelerated by online technologies.

One of the consequences of the third industrial revolution is online education, culminating with MOOC in the 2012, as such courses were expected to replace traditional 
(in-person) education and expand access to university education to millions of students from all over the world. The revolution of higher education through online courses is still ongoing, but it is rather expected to integrate high-quality, synchronous learning environments with online technologies that enable students to develop faster their skills. There are authors who separate activities between synchronous and personal activities (intrinsic exploration, coaching, mentoring) and those that can be easily moved online (content transfer, production, creation) (Staton, 2012). In the context of an increase in online content delivery and access to information, these components of the educational experience (showing a close relationship between the teacher and the student) will become more and more valuable and can not be so slightly replaced by technology.

Online and technology-based education in universities allow for a more effective teaching, regardless of student training and the opening of campuses to a global community of both teachers and students.

The third industrial revolution has brought teachers to an environment where access to information is free and immediate, where the focus is on active learning, which attaches great importance to collaboration between different teams (Maur, 2009). Many of the responses to reform in STEM education have led to greater emphasis on arts and interpersonal skills integrated into a more interdisciplinary curriculum.

Wider-scale responses to changing realities in recent years have led to the emergence of new institutions with more global and interdisciplinary plans and a greater emphasis on close collaboration among students (e.g. interdisciplinary curriculum of Eastern and Western culture literature and philosophy and several interdisciplinary science courses, as well as several Modern Social Thought and Comparative Social Inquiry courses that allow students to collaborate and discuss prominent themes such as identity, family, and social responsibility in the globalized emerging world of the 21st century).

The fourth industrial revolution is defined as the result of the effects of integrating and combining multiple "exponential" technologies, such as artificial intelligence, biotechnologies and nanomaterials. Synthetic organisms are an example of emerging reality in the fourth industrial revolution, bodies created using robotic assembly lines where nanomaterials considerably improve production efficiency.

This extends the paradigm of the industrial revolution to a future where there will be no more of the industrialized elements (centralized factories, massive labor force in large corporations). An extremely well-known phenomenon is the exponential growth of computer power and a lower cost of storage, which undergoes a geometric relationship known as Moore's Law.

There are authors who consider that the fourth industrial revolution is the transition to renewable energy resources due to biotechnological discoveries. This approach fits into the paradigm of the industrial revolution, with new energy sources and concrete predictions about bio-economy, which will occupy an increasingly important place

(Philp, 2018).

The impact of these technologies is not as well known as the deep and rapid changes they bring. Tertiary education responses are urgent because the social impact of emerging technologies or the damage they cause depends on how they are used, as well as the irreversible loss of control over networks with artificial intelligence that have greater autonomy in the financial sectors and urban infrastructure.

Important changes are required in the science and technology curriculum so that students can develop their ability in rapidly developing areas (genomics, data science, and robotics). A STEM adapted curriculum for the fourth industrial revolution would 
reconsider the traditional curriculum of primary sciences (biology, chemistry and physics) and would give the importance of computer science training as a form of literacy in the fourth industrial revolution.

Any change-oriented educational plan must take into account the results of the third industrial revolution, continuing the development of hybrid and personal online training, as well as integrating videoconferencing globally and asynchronous educational resources. Combined training and optimization of flipped and online courses will create more effective learning environments, where adaptation is a key process.

Any effective education strategy should also include a deep analysis of the human condition, the ways in which new technologies and economic power impact on people at all socioeconomic levels and threats in an interconnected world in a way that encourages intercultural exchanges and respect for freedom and human rights, thus favoring the interdisciplinary and global curriculum. Strategies should aim at developing the intellectual capital of universities and the generic conceptual skills for students (Bratianu \& Bejinaru, 2017; Bratianu \& Vatamanescu, 2017).

An interesting approach that meets the requirements of the Fourth Industrial Revolution is that of the World Economic Forum, which brings into focus the necessary skills for the 21st century (foundational literacy, competencies, character qualities). According to a report, the ability to solve complex problems, critical thinking, creativity, coordination, emotional intelligence, negotiation, cognitive flexibility is among the top skills required by employers by 2020 .

In the field of education there are two phenomena that are gradually increasing, the international mobility of students and the development of transnational tertiary education, a phenomenon present mainly on the Asian continent. The number of students enrolled in tertiary education outside their home countries increased from 1.3 million in 1990 to 5 million in 2014. (ICEF Monitor, 2015). With the fourth industrial revolution, international mobility will continue to grow, so that by 2025 an estimated 8 million students are expected. As regards transnational tertiary education, it is subject to systemic changes resulting from technological evolution and digitization. The phenomenon shows how education strategies are built and adapted by state and nonstate agents. In addition to collaborations and partnerships between universities, there is also an increase in private and non-governmental sectors involved in the delivery of educational programs (e.g. online and distance learning). There is no unanimously accepted definition of transnational education. According to UNESCO, it is defined as teachers in a different country from the institution they belong to. Other authors define transnational education through 3 waves of cross-border flows: (1) students traveling to study in the host country; (2) collaborations through twinning programs; (3) creating groups on foreign markets and developing online courses through information and communication technology. Virtual universities (online educational activities and services) seem to be the future of tertiary education.

\section{Methodology}

This paper aims at a thorough analysis of the main changes taking place in the educational environment in relation to the fourth industrial revolution, so that human capital can respond to the needs and demands of the increasingly complex labor market, following the trends in the field of science and technology.

Fundamental research pursues the understanding and phenomenological description of the links between the educational environment and the technological progress. Thus, the article constitutes an introduction to higher education in relation to 
the permanent and rapid changes in the information and telecommunications technology field.

It is important that the entire educational environment is able to adapt to new technologies. While technology is considered to be one of the main sources of economic progress, it has also generated cultural anxiety over time, putting pressure on employment, insecurity at work, increasing inequality, and even "technological" unemployment.

\section{Results and discussions}

Transnational mobility and links created in tertiary education have become deeply and wider as a result of the changes of the Third Industrial Revolution. With the boom of the fourth industrial revolution, such processes are intensifying and accelerating.

Nowadays, higher education institutions have adopted "globalization" or "internationalization" in ways that strongly reflect technological impulses (strategies to increase the growth of number of students while they participate in educational or transnational mobility as alternatives to overcoming the local barriers to access higher education and labor market.

Another point is the connection between human learning and adaptive human behavior, which can be identified by fighting and flight responses, linguistic capability, motor skills, verbal abilities, attitude capacity (Visser, 2017). The fourth industrial revolution changes many parameters of human existence, which means that human learning should be seen as a complex system.

The first three industrial revolutions have brought major changes in society, leading to a proliferation of curricular innovation and the emergence of educational institutions. Unlike the previous ones, the fourth industrial revolution also brings attention to the impact of several technologies with cost reductions and productivity gains. Such a technological advance needs a proactive response from the educational sector compared to the gradual evolution of society and the subsequent response of the institutions, as happened in previous revolutions.

The impact of new emerging technologies requires a reconsideration of the curriculum in higher education to enable students to fully understand individual technologies, then to be able to analyze and anticipate the evolution of technology, environment and sociopolitical network systems.

The STEM curriculum will need to focus on emerging technologies so that new workforce created must be ble to develop new applications and products, but also to interpret the effects of these technologies on society and make ethical and sustainable use of science and technology.

Economic progress and prosperity take place with investments in intangible capital, resources that are increasingly important for the new economy.

\section{References}

Atkeson, A. and Kehoe, P.J. (2006). Modeling the Transition to a New Economy. Federal Reserve Bank of Minneapolis, Research Department Staff Report 296.

Bratianu, C. \& Bejinaru, R. 92017). Knowledge strategies for increasing IC of universities. In Lopez, I.T. \& Serrasqueiro, R. (Eds.). Proceedings of the 9th European Conference on Intellectual Capital (pp. 34-42), Instituto Universitario de Lisboa (ISCTE), Portugal, 6-7 April 2017. Reading: Academic Conferences and Publishing International. 
Bratianu, C. \& Vatamanescu, E.M. (2017). Students' perception on developing conceptual generic skills for business: A knowledge-based approach. VINE Journal of Information and Knowledge Management Systems, 47(4), 490-505.

Eliot, L.C. (1869). The New Education, The Atlantic Monthly, XXIII.

ICEF Monitor (2015). The state of international student mobility in 2015. Retrieved from http://monitor.icef.com/2015/11/the-state-of-international-student-mobilityin2015/

Kondratieff, N.D. \& Stolper, W. F. (1935). The Long Waves in Economic Life. Journal of Economic Statistics, 17, no. 6, 105-115.

Mazur, E. (2009). Farewell, Lecture?, Science 323, no. 5910, 50-51.

OECD (2013). Education Indicators in Focus - 2013/05 (July). Retrieved from http://www.oecd.org/edu/skills-beyond-school/EDIF\%202013--N\%C2\%B014\% 20\%28eng\%29-Final.pdf.

Philp, J. (2018). The bioeconomy, the challenge of the century for policy makers, New Biotechnology 40, part. A: 11-19. https://doi.org/10.1016/j.nbt.2017.04.004

Staton, M.(2012). Disaggregating the Components of a College Degree. Retrieved from http://www.aei.org/wp-content/uploads/2012/08/-disaggregating-thecomponents-of-a-college-degree_184521175818.pdf.

UNESCO-CEPES (2000). Code of Good Practice in the Provision of Transnational Education, Bucharest: UNESCO/Council of Europe.

Visser, J. (2017). The role of human learning in the information age: challenges and opportunities for Latin America and the rest of us, http://www.learndev. org/dl/HumanLearnInfoAge.pdf.

World Economic Forum (2016). The Future of Jobs: Employment, Skills and Workforce Strategy for the Fourth Industrial Revolution.

Yale University (1828). Reports on the Course of Instruction in Yale College: by a Committee of the Corporation and the Academical Faculty. New Haven: Hezekiah Howe. 